\section{Heart Rate Variability before and after Antidepressant Treat- ment among Patients with Major Depressive Disorder: a Role for Adjunctive Seda- tive-Hypnotics?}

\author{
Hsin-An Cha* \\ Department of Psychiatry, Tri-Service General Hospital, National Defense
} Medical Center, Taipei, Taiwan
As specialists in cardiac autonomic dysregulation in depression, our research team members noted with interest, the paper in Journal of Psychosomatic Research in 2015 by Seldenrijk and co-workers, which reported that CVD incidence over 6 years of follow-up was particularly increased in depressed subjects with more severe symptoms and in those using benzodiazepines [1]. The result of the aforementioned research was the rationale behind our psychophysiological approach to discuss the possible underlying mechanism of these findings. Major Depressive Disorder (MDD) has a prevalence ranging between 8 and 12\% worldwide, and will become the second biggest disease of burden by 2020, ranked just behind Cardiovascular Disease (CVD) [2]. Depressed patients have been shown to have an augmented risk of cardiovascular morbidity and mortality [3,4]. Specifically, Angst et al., [5] reported that MDD patients face a greater risk of cardiovascular mortality than general population, with the relative cardiovascular standardized mortality rates being 1.36 for MDD. Even though the definite mechanisms for this cardiac vulnerability are unknown, depression-associated reduction in Heart Rate Variability (HRV) is thought to be an important pathophysiological factor for this cardiac vulnerability $[6,7]$. Heart rate variability refers to the complex beat-to-beat variation in Heart Rate (HR) produced by the interplay of sympathetic and parasympathetic neural activity at the sinus node of the heart. A high degree of HRV aids healthy cardiac activity and provides a protective effect against myocardial infarction and heart failure, [8] whereas low HRV is an indicator of dysregulated cardiac autonomic

${ }^{*}$ Corresponding author: Hsin-An Cha, Department of Psychiatry, Tri-Service General Hospital, National Defense Medical Center, No. 325, Cheng-Kung Road, Sec. 2, Nei-Hu District, Taipei, 114, Taiwan, ROC, Tel : +886 287927220; Fax: +886 287927221; E-mail: chang.ha@mail.ndmctsgh.edu.tw

Citation: Cha H (2016) Heart Rate Variability before and after Antidepressant Treatment among Patients with Major Depressive Disorder: A Role for Adjunctive Sedative-Hypnotics? J Psychiatry Depress Anxiety 2: 005.

Received: April 29, 2016; Accepted: May 31, 2016; Published: June 14, 2016 function and is associated with poor health [9] and an increased risk of CVD and mortality [6].

There has been an argument on the inconsistent findings regarding whether the observed reduction in HRV is inherent in depression $[10,11]$ or due to the effect of antidepressants $[12,13]$. Research in this area has been hampered by the enrollment of patients with psychiatric and/or physical comorbidities that may confound HRV results. For example, MDD is frequently comorbid with anxiety disorders; approximately $20 \%$ of the patients with a lifetime diagnosis of MDD retrospectively report having had Generalized Anxiety Disorder (GAD) [14]. Previous research showed that GAD per se $[15,16]$ were associated with decreased HRV.

A recent study indicated that unmedicated and physically healthy MDD patients with and without comorbid GAD had reduced HRV, and that those with comorbid GAD showed greater reductions in HRV [17]. Thus, a well-suited sample is needed to better examine the true effects of MDD on HRV. Our recent study showed that physically healthy, non-comorbid, and unmedicated patients with MDD had reduced HRV compared to healthy subjects, and that individuals with more severe depression are likely to have lower HRV than those with less severe depression [18]. These results point to a possible underlying mechanism behind the greater risk of cardiovascular mortality in MDD patients and provide further evidence that support the argument that the effect of reduced HRV is inherent in depression $[11,17]$.

Most licensed antidepressants cannot restore the reduced HRV in depression, although they do effectively improve the depressive symptoms [11]. This phenomenon, on the one hand, reflects that an affective illness such as MDD might have residual effects on neurophysiological systems, as proposed previously $[19,20]$. On the other hand, it questions if any antidepressant can increase HRV in depressed patients and thereby conferring HRV mediated protective effects against increased risks for CVDs. Tricyclic Antidepressants (TCAs) are widely known to reduce parasympathetic tone and, thereby, HRV [11,21]. Evidence has pointed to the possibility of newer classes of antidepressants that act as serotonin and norepinephrine reuptake inhibitors to cause reduction in HRV [22-24], with effects less pronounced than those of TCAs. [25] Other evidence suggested that selective serotonin reuptake inhibitors may decrease HRV [23] but have a lower impact on HRV than TCAs [13]. The effects of agomelatine, a recently introduced antidepressant, on HRV in depressed patients are not well known yet. The pharmacology of agomelatine is unique among licensed antidepressant drugs, as it possesses both melatonergic MT1/MT2 agonistic and 5-hydroxytryptamine $e_{2 c}$ antagonistic properties but no ability to interfere with the neuronal reuptake of serotonin, norepinephrine, or dopamine $[26,27]$. Our recent study showed that agomelatine monotherapy increased cardiac vagal tone, suggesting that it has a favorable cardiovascular safety profile [28]. This may be due to agomelatine's unique mode of action: a synergy between melatonergic and $5-\mathrm{HT}_{2 \mathrm{c}}$ receptors. As suggested by a recent review, activation of melatonergic receptors modulates the tone of the autonomic nervous system [29]. Specifically, acute treatment with melatonin increased cardiac vagal 
Citation: Cha H (2016) Heart Rate Variability before and after Antidepressant Treatment among Patients with Major Depressive Disorder: A Role for Adjunctive Sedative-Hypnotics? J Psychiatry Depress Anxiety 2: 005.

tone [30] and attenuated sympathetic tone [31], whereas, chronic treatment led to the inhibition of sympathetic activity [32] and the improvement of baroreflex function [33]. On the other hand, activation of serotonergic $5-\mathrm{HT}_{2 \mathrm{c}}$ receptors in the Nucleus Tractus Solitarius neurons inhibits vagal outflow to the heart [34], and this inhibitory action can be prevented by a selective $5-\mathrm{HT}_{2 \mathrm{c}}$ receptor antagonist [35]. Nonethelss, the promising result regarding the effect that agomelatine has on HRV warrants further future research in various clinical contexts.

Clinical guidelines recommend monotherapy antidepressants for the treatment of MDD [36,37]. In real-world clinical practice, however, sedative-hypnotics are often prescribed together with antidepressants to treat comorbid anxiety and insomnia symptoms, although these drugs have few or no antidepressive effects [38]. Clinicians should be cautious when adding sedative-hypnotics to agomelatine for the treatment of patients with depression, since there are suggestions that benzodiazepines may lose their efficacy with long-term administration and that their chronic use carries risks of dependence. In addition, there is a suggestion that sedative-hypnotics per se markedly influence HRV, possibly through a central $\gamma$-Aminobutyric Acid mechanism involved in cardiac vagal control of heart rate $[39,40]$. This effect has been understated in the literature about the effect of antidepressants on HRV, possibly because earlier cross-sectional studies found that depressed participants taking only benzodiazepines did not differ from controls with respect to HRV $[12,23]$. However, there is much evidence from human studies showing HRV reducing effects associated with commonly used sedative-hypnotics including alprazolam [41], zolpidem [42], lorazepam [43,44], midazolam $[43,45,46]$ and clonazepam [47]. These finding raises the important question of whether the HRV reducing effect of benzodiazepines is a possible mechanism behind benzodiazepine use-associated additional CVD risk in depressed patients [1]. If this is the case, then whether adding sedative-hypnotics to agomelatine would erase the potential beneficial effect of agomelatine monotherapy on HRV is to be a case of concern. Further randomized, placebo-controlled studies are needed to answer these questions.

All in all, MDD is associated with reduced resting-state HRV. Agomelatine monotherapy may have a beneficial effect on HRV in depressed patients. In real-world clinical practice, however, clinicians should weigh the pros and cons when adding sedative-hypnotics along with agomelatine for the treatment of depressed patients considering that agomelatine's beneficial effects may be offset by the potential negative effects of adjunctive sedative-hypnotics on HRV.

\section{References}

1. Seldenrijk A, Vogelzangs N, Batelaan NM, Wieman I, van Schaik DJ, et al. (2015) Depression, anxiety and 6-year risk of cardiovascular disease. J Psychosom Res 78: 123-129.

2. Murray CJ, Lopez AD (1997) Alternative projections of mortality and disability by cause 1990-2020: Global Burden of Disease Study. Lancet 349: 14981504.

3. Barth J, Schumacher M, Herrmann-Lingen C (2004) Depression as a risk factor for mortality in patients with coronary heart disease: a meta-analysis. Psychosom Med 66: 802-813.

4. Nicholson A, Kuper H, Hemingway $H$ (2006) Depression as an aetiologic and prognostic factor in coronary heart disease: a meta-analysis of 6362 events among 146538 participants in 54 observational studies. Eur Heart J 27: 2763-2774.

5. Angst $\mathrm{F}$, Stassen $\mathrm{HH}$, Clayton PJ, Angst J (2002) Mortality of patients with mood disorders: follow-up over 34-38 years. J Affect Disord 68: 167-181.
6. Thayer JF, Lane RD (2007) The role of vagal function in the risk for cardiovascular disease and mortality. Biol Psychol 74: 224-242.

7. Thayer JF, Yamamoto SS, Brosschot JF(2010). The relationship of autonomic imbalance, heart rate variability and cardiovascular disease risk factors. Int J Cardiol 141: 122-131.

8. Bigger JT Jr, Kleiger RE, Fleiss JL, Rolnitzky LM, Steinman RC, et al. (1988) Components of heart rate variability measured during healing of acute myocardial infarction. Am J Cardiol 61: 208-215.

9. Dekker JM, Crow RS, Folsom AR, Hannan PJ, Liao D, et al. (2000) Low heart rate variability in a 2-minute rhythm strip predicts risk of coronary heart disease and mortality from several causes: the ARIC Study. Atherosclerosis Risk In Communities. Circulation 102: 1239-1244.

10. Berger S, Kliem A, Yeragani V, Bär KJ (2012) Cardio-respiratory coupling in untreated patients with major depression. J Affect Disord 139: 166-171.

11. Kemp AH, Quintana DS, Gray MA, Felmingham KL, Brown K, et al. (2010) Impact of depression and antidepressant treatment on heart rate variability: a review and meta-analysis. Biol Psychiatry 67: 1067-1074.

12. Licht CM, de Geus EJ, Zitman FG, Hoogendijk WJ, van Dyck R, et al. (2008) Association between major depressive disorder and heart rate variability in the Netherlands Study of Depression and Anxiety (NESDA). Arch Gen Psychiatry 65: 1358-1367.

13. O'Regan C, Kenny RA, Cronin H, Finucane C, Kearney PM (2014) Antidepressants strongly influence the relationship between depression and heart rate variability: findings from The Irish Longitudinal Study on Ageing (TILDA). Psychol Med 45: 623:636.

14. Kessler RC, DuPont RL, Berglund P, Wittchen HU (1999) Impairment in pure and comorbid generalized anxiety disorder and major depression at 12 months in two national surveys. Am J Psychiatry 156: 1915-1923.

15. Pittig A, Arch JJ, Lam CW, Craske MG (2013) Heart rate and heart rate variability in panic, social anxiety, obsessive-compulsive, and generalized anxiety disorders at baseline and in response to relaxation and hyperventilation. Int J Psychophysiol 87: 19-27.

16. Thayer JF, Friedman BH, Borkovec TD (1996) Autonomic characteristics of generalized anxiety disorder and worry. Biol Psychiatry 39: 255-266.

17. Kemp AH, Quintana DS, Felmingham KL, Matthews S, Jelinek HF (2012) Depression, comorbid anxiety disorders, and heart rate variability in physically healthy, unmedicated patients: implications for cardiovascular risk. PLoS One 7: 30777

18. Licinio J, Wong ML (2003) Data from the Northern Finland 1966 Birth Cohort support an association between depression and immune function. Mol Psychiatry 8: 711-712.

19. Carney RM, Freedland KE, Stein PK, Skala JA, Hoffman P, et al. (2000) Change in heart rate and heart rate variability during treatment for depression in patients with coronary heart disease. Psychosom Med 62: 639-647.

20. Post RM (1992) Transduction of psychosocial stress in to the neurobiology of recurrent affective disorder. Am J Psychiatry 149: 999-1010.

21. Kemp AH, Brunoni AR, Santos IS, Nunes MA, Dantas EM, et al. (2014) Effects of depression, anxiety, comorbidity, and antidepressants on resting-state heart rate and its variability: an ELSA-Brasil cohort baseline study. Am J Psychiatry 171: 1328- 1334.

22. Chang JS, Ha K, Yoon IY, Yoo CS, Yi SH, et al. (2012) Patterns of cardiorespiratory coordination in young women with recurrent major depressive disorder treated with escitalopram or venlafaxine. Prog Neuropsychopharmacol Biol Psychiatry 39: 136-142.

23. Licht CM, de Geus EJ, van Dyck R, Penninx BW (2010) Longitudinal evidence for unfavorable effects of antidepressants on heart rate variability. Biol Psychiatry 68: 861-868.

24. Terhardt J, Lederbogen F, Feuerhack A, Hamann-Weber B, Gilles M, et al. (2013) Heart rate variability during antidepressant treatment with venlafaxine and mirtazapine. Clin Neuropharmacol 36: 198-202. 
Citation: Cha H (2016) Heart Rate Variability before and after Antidepressant Treatment among Patients with Major Depressive Disorder: A Role for Adjunctive Sedative-Hypnotics? J Psychiatry Depress Anxiety 2: 005.

25. Kemp AH, Brunoni AR, Santos IS, Nunes MA, Dantas EM, et al. (2014) Effects of depression, anxiety, comorbidity, and antidepressants on resting-state heart rate and its variability: an ELSA-Brasil cohort baseline study. Am J Psychiatry 171: 1328-1334.

26. de Bodinat C, Guardiola-Lemaitre B, Mocaer E, Renard P, Munoz C, et al. (2010) Agomelatine, the first melatonergic antidepressant: discovery, characterization and development. Nature reviews. Drug discovery 9: 628-642.

27. Demyttenaere K (2011) Agomelatine: a narrative review. Eur Neuropsychopharmacol 21: 703-709.

28. Yeh TC, Kao LC, Tzeng NS, KuoTB, Huang SY, et al. (2016) Heart rate variability in major depressive disorder and after antidepressant treatment with agomelatine and paroxetine: Findings from the Taiwan Study of Depression and Anxiety (TAISDA). Prog Neuropsychopharmacol Biol Psychiatry 64: 60 67.

29. Pechanova O, Paulis L, Simko F (2014) Peripheral and central effects of melatonin on blood pressure regulation. Int J Mol Sci 15: 17920-17937.

30. Nishiyama K, Yasue H, Moriyama Y, Tsunoda R, Ogawa H, et al. (2001) Acute effects of melatonin administration on cardiovascular autonomic regulation in healthy men. Am Heart J 141: 9.

31. Yildiz M, Sahin B, Sahin A (2006) Acute effects of oral melatonin administration on arterial distensibility, as determined by carotid-femoral pulse wave velocity, in healthy young men. Experimental and clinical cardiology 11: 311 313.

32. Girouard H, Chulak C, LeJossec M, Lamontagne D, de Champlain J (2003) Chronic antioxidant treatment improves sympathetic functions and beta-adrenergic pathway in the spontaneously hypertensive rats. J Hypertens 21 : 179-188.

33. Girouard H, Denault C, Chulak C, de Champlain J (2004) Treatment by n-acetylcysteine and melatonin increases cardiac baroreflex and improves antioxidant reserve. Am J Hypertens 17: 947-954.

34. Jordan D (2005) Vagal control of the heart: central serotonergic (5-HT) mechanisms. Exp Physiol 90: 175-181.

35. Sévoz-Couche C, Spyer KM, Jordan D (2000) Inhibition of rat nucleus tractus solitarius neurones by activation of $5-\mathrm{HT} 2 \mathrm{C}$ receptors. Neuroreport 11 : 1785-1790.

36. Bauer M, Pfennig A, Severus E, Whybrow PC, Angst J, et al. (2013) World Federation of Societies of Biological Psychiatry (WFSBP) guidelines for biological treatment of unipolar depressive disorders, part 1: update 2013 on the acute and continuation treatment of unipolar depressive disorders. World J Biol Psychiatry 14: 334-385.
37. Gelenberg AJ (2010) A review of the current guidelines for depression treatment. J Clin Psychiatry 71: 15.

38. Valenstein M, Taylor KK, Austin K, Kales HC, McCarthy JF, et al. (2004) Benzodiazepine use among depressed patients treated in mental health settings. Am J Psychiatry 161: 654-661.

39. Farmer MR, Ross HF, Chowdhary S, Osman F, Townend JN, et al. (2003) GABAergic mechanisms involved in the vagally mediated heart rate response to muscle contraction as revealed by studies with benzodiazepines. Clin Auton Res 13: 45-50.

40. Farmer MR, Vaile JC, Osman F, Ross HF, Townend JN, et al. (1998) A central gamma-aminobutyric acid mechanism in cardiac vagal control in man revealed by studies with intravenous midazolam. Clin Sci (Lond) 95: 241-248.

41. Cubuk R, Tasali N, Yilmazer S, Gokalp P, Celik L, et al. (2011) Effect of an oral anxiolytic medication and heart rate variability on image quality of 64-slice MDCT coronary angiography. Radiol Med 116: 47-55.

42. Machado C, Estevez M, Rodriguez R, Perez-Nellar J, Chinchilla M, DeFina $P$, et al. (2014) Zolpidem arousing effect in persistent vegetative state patients: autonomic, EEG and behavioral assessment. Current pharmaceutical design 20: 4185-4202.

43. Agelink MW, Majewski TB, Andrich J, Mueck-Weymann M (2002) Short-term effects of intravenous benzodiazepines on autonomic neurocardiac regulation in humans: a comparison between midazolam, diazepam, and lorazepam. Crit Care Med 30: 997-1006.

44. Vogel LR, Muskin PR, Collins ED, Sloan RP (1996) Lorazepam reduces cardiac vagal modulation in normal subjects. J Clin Psychopharmacol 16: $449-453$

45. Michaloudis D, Kochiadakis G, Georgopoulou G, Fraidakis O, Chlouverakis $\mathrm{G}$, et al. (1998) The influence of premedication on heart rate variability. Anaesthesia 53: 446-453.

46. Win NN, Fukayama H, Kohase H, Umino M (2005) The different effects of intravenous propofol and midazolam sedation on hemodynamic and heart rate variability. Anesth Analg 101: 97-102.

47. Baker B, Khaykin Y, Devins G, Dorian P, Shapiro C, et al. (2003) Correlates of therapeutic response in panic disorder presenting with palpitations: heart rate variability, sleep, and placebo effect. Can J Psychiatry 48: 381-387. 